\title{
DE LA TESIS DE LA DOBLE NATURALEZA DE ALEXY A UN "IUSNATURALISMO MODERADO": UNA PROPUESTA DE COMPRENSIÓN DE LOS DERECHOS FUNDAMENTALES IMPLÍCITOS A PARTIR DE LA JURISPRUDENCIA CONSTITUCIONAL DE PERÚ Y CHILE
}

\author{
FROM ROBERT ALEXY'S THEORY OF THE DUAL NATURE TO A \\ "MODERATE NATURAL LAW THEORY". A PROPOSAL FOR THE \\ UNDERSTANDING OF IMPLIED FUNDAMENTAL RIGHTS BASE ON \\ THE CONSTITUTIONAL CASE-LAW OF PERU AND CHILE.
}

\section{José Chávez-Fernández Postigo* Piero Ríos Carrillo**}

\begin{abstract}
RESUMEN: Este trabajo parte del examen comparativo de la jurisprudencia de los Tribunales Constitucionales de Perú y de Chile respecto de los derechos fundamentales implícitos a través de la tesis de la doble naturaleza del derecho de Robert Alexy. El propósito de dicho examen es evidenciar algunas fortalezas y debilidades de la fundamentación y de la caracterización de los mismos, con el objeto de elaborar una propuesta alternativa y correctiva de comprensión de los derechos implícitos, que sin renunciar a la doble dimensión del derecho planteadas por el no positivismo alexiano, se sitúe más allá de él, en lo que puede denominarse un "iusnaturalismo moderado" respecto de dichos derechos.
\end{abstract}

Palabras clave: Doble naturaleza del derecho, Robert Alexy, iusnaturalismo moderado, derechos fundamentales implícitos, tribunal constitucional peruano, tribunal constitucional chileno.

ABSTRACT: Based on a comparative evaluation of the case law of the Constitutional Courts of Peru and Chile on implied fundamental rights, this work evidences some strengths and weaknesses of the foundation and determination of these rights. The aim of this work is to introduce an alternative account for the understanding of implied fundamental rights. This alternative account does not deny the dual nature of law held by Alexy's non-positivism, but it goes further and it can be identified as a "Moderate Natural Law Theory" approach of those rights.

Keywords: The Dual nature of law, Robert Alexy, moderate natural law theory, implied fundamental rights, constitutional court of Peru, constitutional court of Chile.

\footnotetext{
Doctor en Derecho por la Universidad de Zaragoza, España. Profesor de Filosofía del Derecho de la Universidad Católica San Pablo, Arequipa, Perú. Investigador CONCYTEC. Dirección postal: Urb. Campiña paisajista s/n, Barrio de San Lázaro, Arequipa, Perú. Dirección electrónica: jchavezfernandez@ucsp.edu.pe. Este artículo ha sido elaborado como resultado del Concurso de Proyectos de Investigación en Ciencias Sociales y Humanidades 2016 de la Universidad Católica San Pablo, Arequipa - Perú. Proyecto 2016-CSH-P04: "De la justificación a la determinación de los derechos implícitos y sus problemas. Un análisis de la jurisprudencia del Tribunal Constitucional peruano". Los autores agradecen los comentarios de Armando Romero Muñoz, y de los miembros del grupo de investigación conformado para desarrollar el proyecto, en concreto Trilce Valdivia Aguilar, Adriana Melgar Rimachi y Nicolás Alarcón Loayza; las críticas y sugerencias de los árbitros anónimos de la Revista Chilena de Derecho; así como también los aportes bibliográficos de María Paz Madrid.

** Estudiante de la Facultad de Derecho en la Universidad Católica San Pablo, Arequipa, Perú. Dirección postal: Urb. Campiña paisajista s/n, Barrio de San Lázaro, Arequipa, Perú. Dirección electrónica: piero.rios@ucsp.edu.pe
} 


\section{INTRODUCCIÓN}

Robert Alexy ha insistido en los últimos años en una tesis que completa y profundiza su modelo no positivista incluyente: el derecho en general y los derechos fundamentales en particular tendrían una doble naturaleza: una dimensión "real o fáctica" y una "ideal o crítica" ${ }^{2}$ Esta tesis ha merecido y merece, sin duda, una atenta discusión por sí misma ${ }^{2}$, sin embargo, en este trabajo ensayaremos una cosa diferente. La tesis alexiana será la herramienta teórica que nos permita evaluar la fundamentación y la caracterización de los derechos fundamentales implícitos que los Tribunales Constitucionales de Perú y Chile han realizado a través de su jurisprudencia, con el objetivo de esbozar una propuesta de comprensión alternativa y correctiva de los mismos desde lo que llamaremos aquí un "iusnaturalismo moderado". En el fondo se trata de un enfoque de los derechos fundamentales implícitos que -sin renunciar a la característica esencial de su doble dimensión- nos permita fundamentarlos y caracterizarlos conjugando mejor, por un lado, la justicia y la seguridad jurídica, y por otro, su aspecto subjetivo y su dimensión institucional.

La perspectiva de nuestra investigación será predominantemente iusfilosófica, por lo que el examen comparativo de la jurisprudencia de los tribunales constitucionales que servirá de punto de partida para el esbozo de nuestra propuesta, pretende suficiencia aunque no exhaustividad. El trabajo constará de tres partes, una que podríamos denominar "descriptiva" (acápites del II al IV), una segunda, que convendría llamar "evaluativa” (acápite V), y una tercera, que ha de considerarse "normativa" (acápites VI y VII). El itinerario será como sigue. En primer lugar, daremos cuenta brevemente de la tesis alexiana de la doble naturaleza del derecho y en particular de los derechos fundamentales. En segundo lugar, expondremos la fundamentación y la caracterización de los derechos fundamentales implícitos en la jurisprudencia del TC peruano. En tercer lugar, haremos lo propio con la del TC chileno. En cuarto lugar, examinaremos comparativamente ambas comprensiones de dichos derechos a través de la tesis alexiana. En quinto lugar, ensayaremos una fundamentación y una caracterización alternativas y correctivas de los derechos fundamentales implícitos, más allá del no positivismo alexiano. En sexto y último lugar, explicitaremos al menos tres ventajas de nuestro planteamiento.

\section{LA TESIS DE LA DOBLE NATURALEZA DEL DERECHO DE ROBERT ALEXY}

Como es conocido, desde un no positivismo que ha llamado "incluyente", el profesor de la Universidad de Kiel -tras evitar durante muchos años expresarse sobre el con-

\footnotetext{
1 Sobre la tesis general, ver AleXy (2011a) pp. 29 ss.; y respecto de la tesis particular: AleXY (2016a) pp. 34 ss.

2 Podemos destacar en ese sentido los trabajos: Bernal Pulido (2011) pp. 7 ss.; o Sodero (2017) pp. 55 ss.

3 Para Alexy "[l]a tercera versión del no-positivismo, es la [...] incluyente, la cual se encuentra entre los extremos del no-positivismo excluyente y el no-positivismo súper-incluyente. Los planteamientos del no-positivismo incluyente se circunscriben a una posición intermedia de modo que se centran en decir acerca de los defectos morales que: ni siempre socavan la validez jurídica - postura representada por el no-positivismo excluyente, ni que nunca lo hacen, según lo expone el no-positivismo súperincluyente-. En consecuencia, se afirma que los
} 
cepto de "naturaleza" - ha planteado desde hace poco menos de una década que la única característica esencial del derecho es que este tiene una doble naturaleza que comprende necesariamente tanto una dimensión "ideal o crítica" como una "real o fáctica”" La primera dimensión sería una no positiva y estaría expresada en la tesis de que todo derecho formula necesariamente una pretensión de corrección de carácter discursivamente moral; mientras que la segunda sería más bien positiva y estaría representada por los aspectos de la autoridad y de la eficacia social, que son también necesarios para que la moralidad alcance una decisión específica y garantice coercitivamente su ejecución. La primera hace referencia a un principio material o substancial: el de la justicia, el que exigiría la corrección moral de la decisión jurídica. La segunda lo hace más bien a un principio formal: el de la seguridad jurídica, el que implicaría la vinculación de dicha decisión a la autoridad y a la eficacia social. A su modo de ver, la dimensión ideal del derecho, por sí sola, expresaría solo una corrección de "primer orden", en cambio el "segundo orden" de corrección sería más comprehensivo o global, pues se referiría tanto a la dimensión ideal como a la real del derecho en su conjunto5.

En ese sentido, para Alexy, puesto que a menudo los principios de la justicia y de la seguridad jurídica entran en colisión en un sistema jurídico, la naturaleza dual del derecho exigiría necesariamente que haya proporción dialéctica entre ellos para alcanzar la armonía, es decir, la ponderación también sería esencial a este aspecto del derecho ${ }^{6}$. A su juicio, esta tesis abstracta encuentra la determinación de su contenido al interior de un sistema concreto cuya idea central es lo que llama la "institucionalización de la razón". Dicha idea plantea tanto un límite externo o "substancial" que se puede expresar sintéticamente en la versión alexiana de la tesis de Radbruch respecto de que "la extrema injusticia no es derecho" ${ }^{8}$, tanto como un límite interno o "procedimental", representada por la forma política del "constitucionalismo democrático o discursivo", cuyos elementos principales son la democracia y los derechos fundamentales, elementos que tienen también, cada uno, una naturaleza dual.

Pero para Alexy, la justificación de los derechos fundamentales es solidaria de la de los derechos humanos ${ }^{9}$, por lo que se hace necesario ocuparnos primero de su defensa de la existencia de estos últimos, es decir, de su fundamentación ${ }^{10}$. A su juicio, los derechos

defectos morales socavan la validez jurídica solo bajo ciertas condiciones. El no positivismo incluyente está dado en su expresión más destacada en la fórmula de RADBRUCH, la cual en su forma más comprimida, es la siguiente: la injusticia extrema no es derecho". Alexy (2013) pp. 17-18.

4 Ver Alexy (2011a) pp. 29-49; o Alexy (2011b) pp. 75-79. No obstante su novedad, la tesis de la doble naturaleza del derecho habría estado implícita en la tesis alexiana más antigua: aquella acerca de que la argumentación jurídica es un caso especial de la argumentación práctica general. AleXY (2018) p. 255.

5 Confrontar Alexy (2017a) pp. 323-324.

6 Para el profesor alemán: "la ponderación desempeña un papel relevante no solamente en la creación y la aplicación del derecho, es decir, en la praxis jurídica, sino también, en el propio nivel del fundamento del derecho". Alexy (2011a) p. 43.

7 Revisar AleXy (2000) pp. 233 ss.

8 Ver Alexy (2006) p. 229.

9 Confrontar Alexy (2007a) p. 52.

10 Ver Alexy (2016b) pp. 93 ss. 
humanos tendrían una estructura de principios y se caracterizarían por su universalidad, su carácter fundamental, su abstracción, su moralidad y su prioridad ${ }^{11}$. Pero para su existencia lo decisivo sería el aspecto moral, pues tales derechos en tanto que "derechos morales" serían válidos solo si son justificables, justificación "objetivo-subjetiva” que Alexy pretende alcanzar a través de un enfoque complementario "explicativo-existencial" en el que están representadas también respectivamente las dimensiones ideal y real. De tal manera que, mientras que por el aspecto explicativo, ideal u objetivo, los derechos humanos serían discursivamente necesarios -lo que presupondría la capacidad discursiva de la persona ${ }^{12}$-; por el aspecto existencial, real o subjetivo, estos responderían a un interés fáctico del sujeto en el discurso ${ }^{13}$, lo que hace que sea imposible justificar los derechos humanos sin una metafísica, aunque no propiamente "enfática", sino antes bien solo "constructiva"

Para el profesor alemán, con el objeto de que los derechos humanos no solo tengan validez por su corrección moral o ideal sino que alcancen también pleno vigor real, ha de garantizárseles a través de su incorporación positiva, por ejemplo, en el catálogo de derechos fundamentales de una Constitución política ${ }^{15}$. Pero no habría que interpretar por ello que su transformación en derecho positivo - propiamente: en derechos fundamentales o constitucionales- sea una suerte de "solución definitiva", pues a su modo de ver se trataría tan solo de un intento de darles una forma institucional ${ }^{16}$. No obstante ello, la tesis de la naturaleza dual de los derechos fundamentales implicaría al menos una doble necesidad argumentativa, por un lado, que se considere tanto la dimensión ideal como la positiva, y por otro, que se atribuya una primacía prima facie a la autoritativa ${ }^{17}$. Esta naturaleza dialéctica entre lo ideal y lo real implicaría también que en una democracia los derechos fundamen-

\footnotetext{
11 Alexy llega a afirmar "que existe un núcleo de derechos humanos básicos que poseen validez eterna". AlEXY (2016c) p. 64.

12 Para Alexy "[u]na justificación de los derechos es explicativa si consiste en hacer explícito lo que está necesariamente implícito en la praxis humana. Una justificación que hace explícito lo que está necesariamente implícito en la práctica humana sigue las líneas de la filosofía trascendental de Kant. Si la práctica es la práctica de afirmar, preguntar y argumentar, la justificación logra un carácter teórico-discursivo [...]. La práctica discursiva [...] presupone reglas del discurso que expresan las ideas de libertad e igualdad [...]. Sin embargo, las ideas de libertad e igualdad son la base de los derechos humanos. Reconocer a otro individuo como libre e igual es reconocerlo como autónomo. Reconocerlo como autónomo es reconocerlo como persona. Reconocerlo como persona es atribuirle dignidad. Atribuir dignidad a alguien es reconocer sus derechos humanos". AlEXY (2016b) pp. 102-103. Cursivas en el texto.

13 Para el profesor alemán: "[l]a necesidad de tratar al otro como libre e igual en el discurso no implica la necesidad de aceptarlo como libre e igual en la vida social [...]. Este problema [...] deriva de la diferencia entre capacidades e intereses. El argumento explicativo solo puede determinar las capacidades discursivas. Sin embargo tener capacidades discursivas no implica un interés en emplearlas [...]. El interés fuerte en la corrección consiste en tomar en serio las capacidades discursivas en la vida real. Una vez más, esto incluye el interés en resolver conflictos sociales por medio de reglas generadas y controladas discursivamente. Quien desea solucionar conflictos sociales a través de reglas generadas y controladas discursivamente reconoce como libres e iguales a los otros individuos, y esto es tomar en serio los derechos humanos de estos. De este modo, el interés en la corrección hace posible llegar al objeto de nuestra justificación; [...] a los derechos humanos". Alexy (2016b) pp. 104-105.

14 Confrontar Alexy (2016d) pp. 85-89.

15 Ver Alexy (2009) p. 93.

16 Revisar AleXY (2016b) p. 95.

17 Revisar AleXY (2016a) p. 37.
} 
tales puedan entrar en conflicto con ella, por lo que la vida política exigiría que exista un control de constitucionalidad ${ }^{18}$. En su opinión, este -en tanto que se entiende como "una representación argumentativa o discursiva del pueblo" - aspiraría a estar más cerca de la dimensión ideal del derecho que el parlamento, institución que estaría especialmente conectada, más bien, a la dimensión real o autoritativa.

En el acápite $\mathrm{V}$ tendremos oportunidad de apreciar cómo las reflexiones precedentes de Alexy -más allá de que puedan ser suscritas íntegramente- resultan útiles para evaluar favorablemente como "no positivistas" la fundamentación y la caracterización que los tribunales constitucionales de Perú y de Chile hacen de los derechos fundamentales implícitos a través de su jurisprudencia, sin perjuicio de que pueda plantearse también, ya en el acápite VI, aspectos alternativos y correctivos que deban considerarse para su mejora. Pero, por lo pronto, parece importante ofrecer primero una breve síntesis de la jurisprudencia peruana al respecto.

\section{EL TC PERUANOY LA TESIS DE LOS DERECHOS FUNDAMENTALES IMPLÍCITOS}

Antes de centrarnos en lo que el máximo intérprete de la Constitución peruana sostiene respecto de los derechos fundamentales implícitos, haremos una sintética referencia a la fundamentación y a la caracterización que realiza de los derechos fundamentales en general.

En cuanto a lo primero, en consonancia con la Constitución Política del Perú (CPP) que reconoce que "[l]a defensa de la persona humana y el respeto de su dignidad son el fin supremo de la sociedad y del Estado" (artículo 1), para el TC peruano "la dignidad de la persona es el presupuesto ontológico común a todos los derechos fundamentales" ${ }^{19}$ y en ese sentido, puede considerársele su "fundamento, fin y límite" ${ }^{20}$, dado que "no se reduce a la protección de la autonomía moral del ser humano, sino que ella es consecuencia del previo reconocimiento de su condición de fin en sí mismo" ${ }^{21}$. Sin perjuicio de ello, para el máximo intérprete de la Constitución este fundamento no excluye otros, como tendremos oportunidad de apreciar luego.

Por otro lado, si bien el alto tribunal peruano no ha intentado fijar una definición de los derechos fundamentales, ha sostenido - patentemente imbuido por las ideas alexianas ${ }^{22}$ que "las posiciones de derecho fundamental, son los derechos fundamentales en sentido estricto, pues son los concretos atributos que la persona humana ostenta al amparo de las normas (sentidos interpretativos) válidas derivadas directamente de las disposiciones contenidas en la Constitución que reconocen derechos" ${ }^{23}$, sin perjuicio de sostener también que

\footnotetext{
18 Confrontar AleXY (2011a) p. 51.

19 DEMANDa de InCONSTITUCIONALIdAd CONTRA LA LEY Nº 27766 (2002) F.J. 9.

20 MAÑUCA QUIROZ CON RENIEC (2006) F.J. 7.

21 Demanda de InCONSTITUCIONALIDAd CONTRA EL ARTICUlo $3^{\circ}$ DE LA LEY No 28705 (2011) F.J. 53. Sobre esto, confrontar Chávez-Fernández Postigo (2012) pp. 83 ss.

22 Revisar, por ejemplo: AleXY (2007b) pp. 151 ss.

23 ANicama HeRNÁNDEZ CON ONP (2005) F.J. 25. Cursivas en el texto.
} 
se trata de "derechos naturales anteriores a la sociedad y al Estado [...] los cuales han sido progresivamente reconocidos hasta hoy en su legislación positiva como derechos humanos de carácter general" ${ }^{24}$. Por último, cabe dejar anotado por ahora que, como ha evidenciado Castillo Córdova, el TC no hace una distinción en sentido estricto entre "derechos humanos", "derechos fundamentales" y "derechos constitucionales" 25.

En concreto sobre la materia que nos ocupa, el TC -en consonancia con parte importante de la doctrina peruana ${ }^{26}$ - justifica el postulado de unos derechos fundamentales implícitos predominantemente de la siguiente manera:

" $[\mathrm{P}]$ ara que los textos constitucionales y, en particular, aquellos nuevos derechos directamente vinculados con el principio de dignidad no sean desmerecidos en su condición de auténticos derechos fundamentales como consecuencia de la existencia de nuevas necesidades o situaciones, las constituciones suelen habilitar una cláusula de "desarrollo de los derechos fundamentales", cuyo propósito no solo es prestarle el reconocimiento como derechos de la más alta consideración, sino incluso, dotarlos de las mismas garantías de aquellos que sí lo tienen expresamente"27.

La cláusula constitucional peruana a la que alude el TC reza así: “[1]a enumeración de los derechos establecidos en este capítulo [se refiere a los derechos fundamentales reconocidos expresamente en el Capítulo I, CP] no excluye los demás que la Constitución garantiza, ni otros de naturaleza análoga o que se fundan en la dignidad del hombre, o en los principios de soberanía del pueblo, del Estado democrático de derecho y de la forma republicana de gobierno" (artículo 3, CPP) ${ }^{28}$.

A partir de la interpretación de esta cláusula, para el TC son derechos fundamentales los derechos "explícitos", "escritos" o "enumerados", es decir, tanto a) los derechos contenidos en las disposiciones constitucionales del Capítulo I, v.g. el derecho a la vida (artículo 2, inciso 1, CPP) o a la igualdad ante la ley (artículo 2, inciso 2, CPP); como b) los otros derechos que la Constitución garantiza textualmente fuera de ese capítulo, por ejemplo: el derecho a la libertad de iniciativa privada (artículo 58, CPP) ${ }^{29}$.

Pero a su juicio, habría también derechos fundamentales que pueden ser llamados indistintamente "implícitos", "no escritos" o "no enumerados" 30 y lo pueden ser de dos tipos. En primer lugar: a) los derechos de naturaleza análoga a los explícitos, por ejemplo, los derechos reconocidos en los instrumentos internacionales de derechos humanos asumidos por el

\footnotetext{
24 Empresa de TRANSPORTes TURismo Imperial S.A. con MTC (2008) F.J. 84.

25 Confrontar, por ejemplo: CASTILlo Córdova (2007) pp. 99-101, y la bibliografía allí citada.

26 Revisar, por ejemplo: Sosa SACIO (2009) pp. 100-104.

27 Rosado AdANAQUE CON ESSALUd (2003) F.J. 5. Subrayado en el original.

28 Sobre la IX Enmienda de la Constitución de los Estados Unidos de América como antecedente de esta cláusula, confrontar Carpio Marcos (2000) pp. 5 ss.

29 Como ha notado con acierto Carpio Marcos, en el caso peruano, todos los derechos constitucionales deben ser considerados también fundamentales, y son protegidos por los procesos constitucionales de la libertad, aun cuando no estén nominados en el Capítulo I de la Constitución peruana. Revisar Carpio Marcos (2008) pp. 21-22.

30 Ver Rosado Adanaque con Essalud (2003) F.J. 5; o Anicama HeRnANDEZ CON ONP (2005) F.J. 4.
} 
Perú $^{31}$, v.g. el derecho al reconocimiento de la personalidad jurídica ${ }^{32}$. En segundo lugar: b) los otros derechos que se sustentan principalmente en la dignidad humana, como por ejemplo, el derecho al libre desarrollo de la personalidad ${ }^{33}$, o que se sustentan en los otros tres principios a los que se refiere el art. 3 de la Constitución ${ }^{34}$, como el derecho a la verdad en su sentido colectivo ${ }^{35}$, derivado de los principios de Estado social y republicano de Derecho. En ese orden de ideas, para el TC peruano "los derechos fundamentales son la materialización del principio democrático en su faz fundacional al interior del Estado social y democrático de derecho" por lo que "sin perjuicio del reconocimiento de una amplia gama de derechos fundamentales el artículo $3^{\circ}$ de la Constitución, además de la dignidad humana, reconoce a la soberanía popular y al Estado democrático como sus fuentes legitimadoras" 36 .

De tal manera que para el TC, considerando que el ordenamiento jurídico no crea los derechos fundamentales sino que tan solo se limita a reconocerlos ${ }^{37}$, los derechos fundamentales implícitos serían "atributos subjetivos" no previstos originariamente en la Constitución, pero que con el tiempo, pueden ser catalogados por los jueces constitucionales como derechos fundamentales con las mismas consecuencias prácticas que los explícitos ${ }^{38}$, siendo que, a su juicio, "resulta consustancial a las acciones de garantía la protección de derechos consagrados en la Constitución o derivados de la cláusula de derechos no enumerados previstos en el artículo $3 .^{\circ}$ de la Carta Magna" 39 .

31 DEMANDA DE INCONSTITUCIONALIDAD CONTRA EL ARTICULO 22으. INCISO C) DE LA LEY Nº 26397 (2005) F.J. 29-30. La cuarta de las Disposiciones Finales y Transitorias de la CPP establece además que "[l]as normas relativas a los derechos y a las libertades que la Constitución reconoce se interpretan de conformidad con la Declaración Universal de Derechos Humanos y con los tratados y acuerdos internacionales sobre las mismas materias ratificados por el Perú", lo que da pie al TC para señalar que "también apelando a un ejercicio hermenéutico al amparo de una fórmula sistemática o variante de contexto, deducible de las cláusulas contenidas en los instrumentos internacionales relativos a derechos humanos" se pueden establecer derechos fundamentales implícitos o contenidos jurídicos más amplios de aquellos derechos que ya cuentan con cobertura constitucional. Confrontar ZÚNIGA LOPEZ CON EPSEL S.A (2007) F.J. 4.

32 Ver AMANQUi RAMOS CON RENIEC (2008) F.J. 10 ss.

33 Revisar Demanda de InCONSTItUCIONALIDAd CONTRA las ORDENANZAS No 212-2005 y No 214-2005 DE LA Municipalidad Distrital de Miraflores (2007) F.J. 47. Aunque luego el TC peruano haya retrocedido optando por identificar el derecho al libre desarrollo de la personalidad con el derecho explícito al libre desarrollo y bienestar del artículo 2, inciso 1 de la CPP. Confrontar DEMANDA DE INCONSTITUCIONALIDAD CONTRA EL ARTICULO $3^{\circ}$ DE LA LEY No 28705 (2011) F.J. 22-23.

34 Revisar VILLANUEVA VALVERDE CON ONP (2005) F.J. 6. El TC peruano señala que "es necesario tener presente que el artículo $3^{\circ}$, concordante con el artículo $43^{\circ}$ de la Constitución, dispone que la enumeración de los derechos establecidos en su capítulo I del Título I no excluye los demás que la Constitución garantiza, ni otros de naturaleza análoga o que se fundan en la dignidad del hombre, o en los principios de soberanía del pueblo, del Estado democrático de derecho y de la forma republicana de gobierno". (F.J. 6). El artículo 43 de la CPP reza así: "[1]a República del Perú es democrática, social, independiente y soberana. El Estado es uno e indivisible. Su gobierno es unitario, representativo y descentralizado, y se organiza según el principio de la separación de poderes”.

35 Revisar VILLEGAS NAMUCHE CON ESTADO PERUANO (2004) F.J. 16 ss.

36 DEMANDA DE INCONSTITUCIONALIDAD CONTRA LA LEY Nº 28617 (2005) F.J. 21.

37 Confrontar TAVARA CAFERINO CON SEDAPAL (2008) F.J. 16.

38 Ver CANCHARI PISCO CON COMSTEA (1999) F.J. 3.

39 Sarmiento Bejarano con Mestanza Robles (2003) F.J. 3. En ese sentido el Código Procesal Constitucional del Perú establece que "El amparo procede en la defensa de los siguientes derechos: [...] Los demás que la Constitución reconoce" (artículo 37, inciso 25). 
En ese sentido, el alto tribunal peruano distingue -en una terminología que no deja de resultar confusa ${ }^{40}$ - entre "derechos implícitos" propiamente hablando, como por ejemplo el derecho al agua potable ${ }^{41}$; y los "contenidos implícitos de derechos viejos" o "contenidos nuevos de derechos escritos". Estos últimos serían, a su juicio, derechos contenidos a su vez en derechos expresamente reconocidos que, sin embargo, resultan susceptibles de ser configurados autónomamente, como por ejemplo el derecho a un plazo razonable, que hace parte del derecho al debido proceso $^{42}$ o el derecho a la objeción de conciencia, que lo hace del derecho a la libertad de conciencia ${ }^{43}$.

Para terminar, es importante señalar que como parte de la procedimiento jurisprudencial para el reconocimiento de estos derechos implícitos, el TC peruano advierte acerca de que el recurso al artículo 3 de la Constitución debe ser excepcional, dado que la jurisdicción constitucional carece de "legitimidad democrática directa", por lo que ha de recurrir a dicha cláusula solo cuando el derecho fundamental "cuya esencialidad ética es indiscutida y que es necesario proteger, no derive razonablemente de la semántica de los derechos expresamente enumerados por la Norma Fundamental" 44 , lo que evitará "recurrir constantemente a la cláusula constitucional de los derechos "no enumerados" y, con ello, desvirtuar el propósito para el cual fue creada” ${ }^{35}$.

\section{EL TC CHILENO Y LA TESIS DE LOS DERECHOS FUNDAMENTALES IMPLÍCITOS}

Para el análisis que nos ocupa en este acápite ensayaremos un desarrollo paralelo -en la medida de lo posible- al realizado en el caso peruano. Haremos primero una breve síntesis de la fundamentación y de la caracterización de los derechos fundamentales en general por parte de la jurisprudencia del TC chileno, para luego pasar revista -también muy sucintamente- a su tratamiento de la tesis de los derechos implícitos.

En relación con la fundamentación de los derechos fundamentales -o, "esenciales", según la fraseología de la Constitución Política chilena (CPR) - encontramos que el alto tribunal, conforme a la tendencia constitucional contemporánea ${ }^{46}$, asume que la dignidad de la persona humana "[e]s la fuente de los derechos esenciales" ${ }^{47}$ y constituye el "[f]un-

\footnotetext{
40 Así lo ha notado, por ejemplo: Castillo Córdova (2008) p. 41.

41 Confrontar TaVARA CAFERINO CON SEDAPAL (2008) F.J. 18.

42 Revisar el artículo 139 de la CPP; y ROSADO ADANAQUE CON ESSALUD (2003) F.J. 5.

43 Confrontar el artículo 2, inciso 3 de la CPP; y ROSADO ADANAQUE CON ESSALUD (2003) F.J. 6.

44 Cinco mil Ciudadanos Contra el artículo $3^{\circ}$ DE LA LeY No 28705 (2011) F.J. 21. Aunque cabe señalar que dicho criterio dista mucho de ser seguido consistentemente por el propio TC, que recientemente ha reconocido el derecho implícito a la negociación colectiva de los trabajadores públicos, existiendo el artículo 28 de la CPP que garantiza explícitamente la negociación colectiva. Confrontar DEMANDA DE INCONSTITUCIONALIDAD CONTRA LA LEY $N^{\circ} 29951$ (2015) F.J. 47; y DEMANDA DE INCONSTITUCIONALIDAD CONTRA DIVERSOS ARTICULOS DE LA LEY $N^{\circ}$ 30057 (2016) F.J. 143.

45 Rosado AdANAQUE CON ESSALUd (2003) F.J. 5.

46 Para una descripción de dicha tendencia y sus implicancias en el constitucionalismo chileno, revisar NASH (2006) p. 1320.

47 Rol No 389, Co 17.
} 
damento de todos los derechos que le son inherentes" ${ }^{38}$. Con ello, conviene referir que el TC chileno encuentra en las nociones de dignidad (artículo 1, CPR), naturaleza humana (artículo 5, inciso segundo, CPR) y los derechos constitucionales (artículo 19, CPR) una vinculación que los constituye como principios y valores básicos de fuerza obligatoria que impregnan toda la Constitución de una finalidad humanista ${ }^{49}$.

Con respecto a la caracterización de los derechos fundamentales, no existe en la jurisprudencia temprana del TC chileno una teoría o, cuando menos, una conceptualización clara de ellos. Si bien en 2007 el Magistrado Vodanovic Schnake, en vía de voto individual, propuso una conceptualización amplia de los derechos fundamentales ${ }^{50}$ a partir de la noción de "[d]erechos subjetivos que corresponden universalmente a todos los seres humanos en cuanto dotados de status de personas" ${ }^{51}$, recién en el Rol No 1.710 de 2010, luego de sentar la posibilidad de nociones plurales relativas a los derechos, el alto tribunal chileno parece haber asumido la tesis de Alexy en cuanto a la caracterización de los derechos fundamentales a la luz de su teoría de los principios $^{52}$, esto es, entender que los mismos son mandatos de optimización o normas de principio $^{53}$.

En concreto, sobre la posibilidad de la existencia de derechos implícitos, la jurisprudencia del TC chileno -secundada por parte importante de la doctrina ${ }^{54}$ - acepta la viabilidad de desprender derechos fundamentales implícitos por vía interpretativa a partir del articulado de la Constitución. Así, en una primera ocasión señaló:

"[U]niversalmente, tanto la doctrina como nuestra Constitución Política reconocen la existencia de derechos, aunque no estén consagrados en el texto constitucional, a menos que esta consagración implique una violación a las normas fundamentales [...]. Esta última expresión significa que los hombres son titulares de derechos por ser tales, sin que sea menester que se aseguren constitucionalmente para que gocen de protección constitucional" 55 .

Cabe señalar, sin embargo, que la forma en la que el TC se ha referido a estos derechos no ha sido uniforme. En efecto, el alto tribunal chileno, al reconocer en un inicio la existencia implícita del derecho al acceso a la información pública en la sentencia ya referenciada, postuló que la disposición de la que emana tal derecho es el artículo 5, inciso segundo de la CPR, el cual establece que el ejercicio de la soberanía reconoce como limitación el respeto a los derechos esenciales que emanan de la naturaleza humana. Aunque valga la pena señalar que, más recientemente, se ha añadido que el mismo derecho se deriva

\footnotetext{
48 Rol No 433, Co 25.

49 Confrontar Rol No 943, Co 30: "Que, como ya se ha señalado, el contenido del artículo 19 de la Carta Fundamental, conjuntamente con sus artículos $1^{\circ}, 4^{\circ}$ y $5^{\circ}$, inciso segundo, de la misma, configuran principios y valores básicos de fuerza obligatoria que impregnan toda la Constitución de una finalidad humanista que se irradia en la primacía que asignan sus disposiciones a la persona humana, a su dignidad y libertad natural, en el respeto, promoción y protección a los derechos esenciales que emanan de la naturaleza humana”.

50 Para una revisión de la doctrina en la que se basó el magistrado, confrontar Nogueira (2005).

51 Ver Rol No 786, voto disidente de Hernán Vodanovic Schnake. \$3.

52 Confrontar: Rol No 1.710 , Co 89 ss.

53 Ver Rol No 1.710, Co 93.

54 Revisar, por ejemplo: Correa Sutil (2011) pp. 47-50; o Contreras Vásquez (2011) pp. 149-185.

55 Rol No 226, Co 25.
} 
también del derecho a la libertad de opinión y de información, reconocidos expresamente en el artículo 19 , inciso $12^{\circ}$ de la Carta Magna ${ }^{56}$.

En otra oportunidad, respecto del derecho implícito a la acción, el TC señaló que este es un derecho derivado del artículo 19 , inciso $3^{\circ}$ de la CPR, al entender que sería un sinsentido que se aseguren constitucionalmente garantías judiciales tales como el derecho de defensa o el derecho a un juez natural si no se entendiera que el texto fundamental asegura también al derecho que sirve de presupuesto para su ejercicio ${ }^{57}$. Conviene aclarar que en esta ocasión se prescindió de la remisión al ya referido artículo 5, inciso segundo.

En el caso del derecho a la identidad personal, su existencia -a veces cuestionada por la doctrina ${ }^{58}$, y otras veces, no sostenida uniformemente por el $\mathrm{TC}^{59}$ - se derivaría del principio de dignidad (artículo 1, inciso primero) y de la normativa de los instrumentos internacionales de derechos humanos (artículo 5, inciso segundo) ${ }^{60}$.

Finalmente, para cerrar este catálogo de ejemplos, cabe señalar que en el caso del derecho a la presunción de inocencia, la argumentación -sin remisión expresa al artículo 5, inciso segundo de la CPR- fue hecha, en una primera oportunidad, enteramente de conformidad con la consagración de dicha garantía en los tratados internacionales de derechos humanos, en específico, el artículo 8.2 de la Convención Americana sobre Derechos Humanos y el artículo 14.2 del Pacto Internacional de Derechos Civiles y Políticos ${ }^{61}$. Sin embargo, en jurisprudencia más reciente, se entendería que también existiría un fundamento para tal derecho en la prohibición expresa de presumir responsabilidad penal, consagrada en el artículo 19 , inciso $3^{\circ}$, párrafo sexto de la $\mathrm{CPR}^{62}$.

Lo que puede concluirse pacíficamente de esta breve exposición de los modos en que el TC chileno argumenta la existencia de ciertos derechos implícitos, es que no se da ni una única forma de hacerlo, ni una sistematización o clasificación de los mismos. De hecho, no queda claro de la sola revista de las sentencias que los reconocen, la existencia de una disposición constitucional expresa que pueda ser identificada excluyentemente como "la cláusula de derechos implícitos" de la CPR. No obstante ello, podría decirse que para la doctrina, el artículo 5, inciso segundo sería la fuente de derivación más clara: mientras que para algunos, su referencia expresa a los derechos garantizados en tratados internacionales ha signi-

\footnotetext{
56 Rol No 2.246, Co 22. En esta ocasión el TC chileno se vio en la posición de "aclarar" su razonamiento en la medida en que, por ejemplo, en el Rol No 634, Co 9 pareció haber fundado la existencia del derecho en cuestión a la luz del artículo $8^{\circ}$ de la CPR, que consagra los principios de probidad publicidad y transparencia.

57 Ver Rol No 946, Co 33.

58 Confrontar Candia Falcón (2014).

59 En efecto, en el marco de los requerimientos de inaplicabilidad del artículo 206 del Código Civil y 50 Transitorio de la Ley No 19.585, existen casos en que el TC chileno lejos de afirmar la existencia de un derecho implícito a la identidad personal ha optado por a) fundar la demanda por la infracción al derecho expreso de igualdad ante la ley, reconocido en el artículo 19, inciso $2^{\circ}$ de la Constitución. (Ver Rol No 1.563 Co 13 ss.) o

b) decidir no inaplicar los artículos impugnados. (Ver Rol 2.408).

60 Rol No 834 Co 22 y más recientemente, Rol No 1340 Co 9 y 10.

61 Rol No 793 Co 7.

${ }^{62}$ Rol No 1351 Co 44.
} 
ficado la adición de nuevos derechos a la $\mathrm{CPR}^{63}$, para otros, dicho inciso sería la fuente de derivación incluso de derechos no positivados en absoluto ${ }^{64}$. Sin embargo, lo cierto es que el TC no ha sido claro ni uniforme en seguir esa tesis, sino que antes bien, parece que las fuentes que ha propuesto han sido tan diversas como sus argumentaciones respecto de cada derecho específico que le ha interesado postular como implícito ${ }^{65}$.

Sin perjuicio de ello, hemos de reconocer que una constante identificable es la vinculación de los derechos implícitos con la dignidad y la naturaleza humana ${ }^{66}$, las cuales constituirían la base axiológica de una argumentación que luego, en la especificidad de cada reconocimiento y determinación concreta, puede combinarse con otras herramientas de derivación que hallen también respaldo en disposiciones constitucionales, las cuales pueden ser: a) derechos expresamente catalogados en el artículo $19^{\mathrm{o} 67}$; b) remisiones al derecho internacional de los derechos humanos ${ }^{68}$; o c) principios fundamentales del Estado, como por ejemplo, el carácter democrático del Estado ${ }^{69}$. Con ello, parece innegable la importancia jurisprudencial de la interpretación del artículo 5, inciso segundo, y del artículo 1 de la CPR, a partir de los cuales se sirve preferentemente el TC chileno para entender que el catálogo de derechos consagrados en el artículo 19 no sea uno de carácter cerrado, sino más bien uno que se encuentre permeable al reconocimiento de otros derechos fundamentales de carácter implícito a partir de la actividad jurisdiccional ${ }^{70}$.

\section{UN EXAMEN COMPARATIVO DE LOS DERECHOS IMPLÍCITOS DESDE LA TESIS DE ALEXY}

Si bien resulta patente que la jurisprudencia del TC peruano presenta -no obstante las inconsistencias evidenciadas- una caracterización que pretende ser más completa y or-

63 Para algunos: "[s]i la protección otorgada en los tratados internacionales es compatible con el texto constitucional, aunque sea más precisa y detallada, o incorpore nuevos derechos, como sucede por ejemplo en el área de los derechos económicos y sociales, este nuevo contenido se adiciona la Constitución, complementando las garantías vigentes a ese momento". Troncoso y Vial (1993) p. 698. No obstante, para otros, dicha referencia podría resultar restrictiva a efectos de derivar derechos no "garantizados" en la Constitución o en los Tratados; ver Fernández González (1989) p. 814. Para algunos otros, la noción misma de derecho fundamental exige considerar como asociado a su concepto su base constitucional; consultar RUIZ-TAGLE VIAL (2003) p. 184.

64 Como parece entender Evans de la Cuadra (1999) Tomo I, pp. 23-24.

65 Para una exposición de tres posibles lecturas de los derechos implícitos en el derecho constitucional chileno, ver Contreras VÁsquez (2011) pp. 154 ss. Y para un ejemplo de fundamentación y caracterización de uno de los derechos implícitos abordados por el TC chileno, ver NogueIra (2007) pp. 245-285. Por otro lado, para una caracterización de la noción de "nuevos derechos", revisar VivanCo MarTíneZ (1998) pp. 109-110.

${ }^{66}$ Aunque el TC chileno no hace referencia a estas constantes en términos de "derechos naturales", lo cierto es que en no pocas oportunidades, sus magistrados, al reflexionar sobre el derecho a la identidad personal, han hecho referencia al carácter natural de este en sus votos concurrentes; al respecto ver, por ejemplo Rol No 1.656. Voto concurrente de los Magistrados Vodanovic Schnake, Fernández Baeza y Peña Torres y señores Fernández Fredes y Viera-Gallo Quesney. $\$ 13$. Asimismo, en la reflexión académica se reconoce que "en el texto constitucional chileno sigue primando una concepción iusnaturalista”, ver, por ejemplo: NASH (2006) p. 1311.

67 Como es el caso del derecho a la acción. Ver Rol No 946, Co 33.

68 Como es el caso del derecho a la presunción de inocencia. Ver Rol No 739 Co 7.

69 Como es el caso del derecho de acceso a la información pública. Ver Rol No 634. Co 9.

70 Confrontar, por ejemplo: CEA Egaña (2012) p. 54. 
denada que la del TC chileno respecto de la tesis de los derechos fundamentales implícitos, por otro lado puede notarse también que hay señas de identidad de fondo comunes a la jurisprudencia de ambos tribunales tanto en la fundamentación como en la caracterización de dichos derechos, y que pueden adscribirse -al menos a grandes rasgos, y más allá de la intención de los magistrados, desde luego- a la tesis no positivista alexiana.

En primer lugar, si nos referimos a la fundamentación de los derechos implícitos, debemos decir que ambos TC remiten de alguna manera, por un lado, a la dimensión no positiva del derecho que Alexy llama "ideal o crítica", a través del reconocimiento de un sustrato ontológico, objetivo, moral y universal que es la fuente de todo derecho fundamental: la dignidad humana; pero por otro, hacen remisión también a la dimensión positiva del derecho -la que Alexy llama "real"- pues creen necesario complementar dicho fundamento moral y universal con algunos de carácter más bien institucional, histórico y contingente como el principio de soberanía del pueblo o del Estado democrático de derecho. Sin embargo, en ninguno de los dos casos queda clara la naturaleza de dicho fundamento moral, ni se ofrece una explicación suficiente de su relación con los fundamentos concurrentes positivos o institucionales.

En segundo lugar, respecto de la caracterización de los derechos implícitos, parece que los tribunales examinados sostienen también dos tesis que responden a ambas dimensiones del derecho, si seguimos a grandes rasgos el enfoque alexiano. Por un lado, que se trata de atributos morales preexistentes al Estado, en tanto que meramente reconocidos, por lo que pueden ser llamados abiertamente "derechos naturales" -si nos remitimos al caso peruano- o al menos situárseles claramente como "derechos esenciales" en dicha esfera semántica -si se toma en serio el tenor del artículo 5, inciso segundo de la CPR, en el caso chileno-, al punto de que son pasibles de ser desarrollados jurisprudencialmente y catalogados junto a los derechos explícitos, si el respeto a la dignidad de la persona así lo exige y sin la participación de los otros poderes del Estado que son los que, paradójicamente, retienen excluyentemente la autoridad de modificar la Carta Magna, como se expresa claramente en las Constituciones de Perú y de Chile ${ }^{71}$. Pero por otro lado, se trataría de posiciones jurídicas que corresponden a normas que son formulaciones interpretativas que se desprenden necesariamente de una o de algunas cláusulas de la Constitución, por lo que, para el desarrollo de un derecho implícito, los altos tribunales deberían invocar necesariamente alguna disposición normativa positiva ${ }^{72}$ la que, no obstante, habría de usarse restrictivamente, como se ha podido apreciar. Es decir, se trataría de una caracterización de los derechos fundamentales implícitos que, en el primer caso, por tutelar la dimensión subjetiva de los

\footnotetext{
71 El artículo 206 de la Constitución peruana señala: "[t]oda reforma constitucional debe ser aprobada por el Congreso con mayoría absoluta del número legal de sus miembros, y ratificada mediante referéndum. Puede omitirse el referéndum cuando el acuerdo del Congreso se obtiene en dos legislaturas ordinarias sucesivas con una votación favorable, en cada caso, superior a los dos tercios del número legal de congresistas". Mientras que los artículos del 127 al 129 de la Constitución chilena establecen un mecanismo más complejo de contrapesos que incorpora al Presidente de la República y a ambas Cámaras del Congreso Nacional, y eventualmente requieren la participación directa de la ciudadanía mediante plebiscito.

72 En el caso peruano, por ejemplo: el artículo 3 de la CPP; mientras que en el caso chileno, por ejemplo: el artículo 5, inciso segundo de la CPR.
} 
derechos vinculada a la justicia, desatiende el elemento institucional de los mismos vinculado a la seguridad jurídica que ofrecen los rigurosos mecanismos de reforma constitucional; mientras que en el segundo caso, por atender al elemento institucional de los derechos representada en el recurso a cláusulas expresas que pretendidamente autorizarían el desarrollo de derechos implícitos, termina tratando a la dignidad humana, de alguna u otra manera, como un elemento subordinado al positivo y no como el fundamento decisivo de todo derecho subjetivo.

Por supuesto que con esto no estamos sugiriendo ni que los Tribunales Constitucionales de Perú y Chile entienden los derechos fundamentales implícitos como lo hace el profesor alemán -sobre todo porque, hasta donde tenemos noticia, Alexy no ha tomado postura clara sobre este asunto $^{73}-$, ni que la tesis alexiana de la doble naturaleza del derecho de matriz constructivista no pueda ser objeto de críticas en orden a su perfeccionamiento. Con el análisis comparativo realizado, sencillamente queremos dejar sentado lo siguiente: que más allá de las tensiones no convenientemente resueltas entre los elementos morales y positivos de la fundamentación y de la caracterización de los derechos fundamentales implícitos, consideramos un acierto que la tesis sobre los mismos compartida por la jurisprudencia constitucional comparada sea una de carácter claramente no positivista, donde se consideren tanto los aspectos "ideal" como "real" del derecho -si seguimos la terminología alexiana-, aun cuando con la misma convicción vayamos a plantear que dicha comprensión pueda mejorarse si es que nos animamos a ir más allá del no positivismo incluyente o constructivista del profesor alemán, hacia lo que llamaremos aquí un "iusnaturalismo moderado".

\section{UNA VISIÓN ALTERNATIVA DE LOS DERECHOS FUNDAMENTALES IMPLÍCITOS: HACIA UN "IUSNATURALISMO MODERADO"}

A continuación intentaremos sentar una plataforma alternativa y correctiva para una fundamentación y una caracterización consecuente de los derechos fundamentales implícitos. Cabe dejar constancia de que se trata de un esbozo de propuesta, y no de una teoría completa, lo que exigiría desarrollos que no es posible abordar aquí.

A diferencia de la de Alexy, nuestra propuesta, por un lado, no se postulará como una fundamentación "semiobjetiva"74 de los derechos, sino antes bien como una "objetiva", aunque sin ser "religiosa", al menos en los términos alexianos ${ }^{75}$. Para decirlo muy sencilla-

\footnotetext{
73 Ver, por ejemplo: AleXy (2017b) p. 35.

74 Para Alexy, respecto de la fundamentación de los derechos humanos que propone: "la objetividad vinculada a la subjetividad es, sin duda, menos que la pura objetividad, pero también algo más que la pura subjetividad. Por esta razón, aunque no es una justificación puramente objetiva, se puede calificar el argumento explicativoexistencial como una justificación genuina de los derechos humanos". AlEXY (2016b) p. 107.

75 Para el profesor alemán: "una justificación religiosa de los derechos humanos se apoya en un fundamento muy fuerte. El que cree que los seres humanos son creados por Dios a su imagen y semejanza tendrá una buena razón para atribuir dignidad a los seres humanos. La dignidad es una base sólida para los derechos humanos [...]. Sin embargo, el argumento tiene una debilidad decisiva. Se considera un argumento únicamente para aquellos que creen en Dios y en la creación del hombre a su imagen y semejanza”. AlExy (2016b) p. 99. Como veremos, nuestra propuesta no exigirá alguna fe religiosa como premisa.
} 
mente: ensayaremos una fundamentación de los derechos implícitos no positivista, pero más tributaria de la tradición de Aristóteles ${ }^{76}$, que de la de Kant ${ }^{77}$. Por otro, nuestro enfoque se traducirá también en una caracterización básica de los derechos en discusión que permita -sin recurrir a la dialéctica ponderación alexiana ${ }^{78}$ - conjugar más convenientemente que los tribunales constitucionales de Perú y Chile, tanto la dimensión no positiva -vinculada especialmente a la justicia y la dimensión subjetiva-, como la positiva -conectada sobre todo a la seguridad jurídica y a la institucionalidad- de los derechos implícitos.

Partiremos de tres tesis que no podremos discutir aqui ${ }^{79}$, pero que creemos que es razonable sostener, al menos si se toma en serio el tenor con el que los principales instrumentos internacionales dan cuenta de los derechos humanos ${ }^{80}$. La primera es que existe una equivalencia material o de contenido moral entre los derechos humanos y los derechos fundamentales ${ }^{81}$. La segunda es que estos están fundamentados en última instancia en una dignidad moral, objetiva y universal común a todos los miembros de la especie humana, y por el mero hecho de serlo ${ }^{82}$. La tercera es que tales derechos cuentan al menos con las siguientes notas básicas: a) son inherentes -en el sentido de esenciales o propios de la naturaleza humana, o de aquello que nos hace humanos-; b) universales -como consecuencia de su inherencia en lo que tiene en común todo ser humano-; c) inalienables -en el sentido de indisponibles para el poder de los Estados-; y d) reconocidos o reconocibles -en el sentido de "naturales" o preexistentes a las instituciones o al ejercicio del derecho positivo que los declara ${ }^{83}-$.

Pero si dichas premisas son correctas, nos parece conveniente sostener que un derecho humano en sentido propio puede ser definido como un bien -en un sentido muy amplio del término- debido en justicia, históricamente imprescindible para el perfeccionamiento o florecimiento de la persona según su dignidad ontológica ${ }^{84}$, y cuyo reconocimiento positivo o institucional abstracto y garantía determinativa resultan prioritarios para todo ordenamiento jurídico. Asimismo, un derecho fundamental en sentido propio sería un derecho humano en sentido propio reconocido expresamente como fundamental por la Constitución Política de un país.

\footnotetext{
76 Confrontar, por ejemplo: Aristóteles (1998) V, 7.

77 Revisar, por ejemplo: Kant (2005) pp. 237 ss.

78 Ver Alexy (2011a) pp. 41 ss.

79 Confrontar Chávez-Fernández Postigo (2012) pp. 129 ss.

80 Por ejemplo: Naciones Unidas, Asamblea General, 217 A (III) (10 de diciembre de 1948), Declaración Universal de Derechos Humanos; Convenio para la Protección de los Derechos Humanos y las Libertades Fundamentales, Roma (4 de noviembre de 1950); Pacto Internacional de Derechos Civiles y Políticos (Nueva York, 16 de diciembre de 1966) o Convención Americana sobre Derechos Humanos (San José, 22 de noviembre de 1969).

81 Ver, por ejemplo: Pérez Luño (2010) pp. 50 ss.

82 Confrontar, por ejemplo: STARCK (2011) pp. 123 ss.; para una opinión contraria, revisar WaLdRON (2013) pp. 9-11.

83 Revisar Hervada (1982) pp. 243 ss., o Cianciardo (2017) pp. 83 ss.; para una opinión contraria, confrontar, por ejemplo: BulYGin (1987) pp. 83-84

84 Para la profundización en el concepto de dignidad en sentido ontológico y su defensa frente la dignidad entendida como "mera autonomía", se puede revisar ChÁvez-Fernández Postigo (2012) pp. 91 ss. Sin perjuicio de ello, algo más se dirá sobre la dignidad ontológica en este acápite y, sobre todo, en el siguiente.
} 
Pero plantear la existencia de un derecho humano o fundamental en sentido propio implica la posibilidad lógica de que los existan también en sentido "impropio", lo que a nuestro juicio podría darse al menos por dos razones distintas, con consecuencias muy diferentes. Un derecho fundamental podría ser llamado "impropio", porque se trata de un derecho no históricamente imprescindible para el perfeccionamiento de la persona según su dignidad ontológica, al que se le ha otorgado, sin embargo, una formulación abstracta o una garantía semejante a la de un derecho humano o fundamental en sentido propio. Pero también podría ser llamado "impropio" -en un sentido enteramente distinto- un aparente derecho que, en realidad, es más bien una lesión -sin duda, socialmente controversial-a un bien debido en justicia, a la que se le ha otorgado erróneamente una formulación abstracta o una garantía semejante a la de un derecho humano o fundamental en sentido propio. Mientras que en el primer caso, lo que habría quedado comprometida sería su fundamentabilidad -es decir: su carácter de ser históricamente imprescindible para el perfeccionamiento de la persona según su dignidad ontológica-; en el segundo caso lo habría sido su juridicidad misma -dicho de otro modo: su condición de bien debido en justicia-, al constituir más bien una lesión a la dignidad ${ }^{85}$.

Si esta plataforma teórica es correcta, estamos en condiciones de ofrecer una fundamentación y una caracterización básicas alternativas de un derecho fundamental implícito en sentido propio. A nuestro modo de ver, se trataría de un derecho humano en sentido propio no reconocido explícitamente como fundamental por la Constitución política de un pais ${ }^{86}$. Correlativamente, un derecho fundamental implícito en sentido impropio sería un derecho humano en sentido impropio argumentado e impuesto autoritativamente como derecho fundamental implícito por un Tribunal Constitucional ${ }^{87}$.

En ese orden de ideas, dicho derecho fundamental implícito en sentido propio -en equilibrio de sus dimensiones "natural" y positiva, y salvaguardando, por un lado, tanto la justicia como la seguridad jurídica, y por otro, tanto la dimensión institucional de los derechos como la subjetiva-, podría ser reconocido por un TC -incluso sin mediar lo que suele llamarse "una cláusula expresa de desarrollo de derechos implícitos"-, pero solo en orden a evitar o a reparar una grave injusticia en un caso específico, es decir, solo frente a una flagrante violación puntual al fundamento moral de todos los derechos: la dignidad humana del justiciable, lesión a un bien humano básico concreto ${ }^{88}$ que además de gozar de un amplio reconocimiento social como tal, no esté protegido ni por un derecho constitucionalmente reconocido de manera expresa, ni por uno de sus contenidos argumentables.

\footnotetext{
${ }^{85}$ En términos del "no-positivismo incluyente" de Alexy, se podría decir que, en este caso, dicho aparente "reconocimiento" sería en realidad una transgresión del umbral de injusticia. Ver AleXY (2013) pp. 16-18.

${ }^{86}$ Como, por ejemplo, el caso chileno del "derecho al acceso a la información pública". Confrontar Rol No 226, Co 25.

87 Un ejemplo peruano es el derecho al "libre desarrollo de la personalidad", al menos entendido de tal manera que su objeto de protección sería "la simple y llana conducta humana, desprovista de algún referente material que le otorgue algún sentido". DEMANDA DE INCONSTITUCIONALIDAD CONTRA LAS ORDENANZAS No 212-2005 y No 214-2005 DE LA Municipalidad Distrital DE Miraflores (2007) F.J. 46.

${ }^{88}$ Revisar Finnis (2011) pp. 59 ss.
} 
Sin embargo, a nuestro juicio, dicho bien interpretado como derecho implícito por parte del TC en un caso puntual, no debería recibir por parte de este una formulación dispositiva abstracta que lo proponga autoritativamente como parte del catálogo de derechos fundamentales en orden a su aplicación normativa erga omnes. En nuestra opinión, esta formulación abstracta típica de las cartas de derechos fundamentales tendría que quedar necesariamente retenida por quien tiene expresamente la potestad de modificar la Constitución, aspecto que nos parece indispensable destacar si se quiere respetar no solo el fundamento moral o iusnatural de los derechos, sino también el institucional o positivo: la soberanía del pueblo $^{89}$. En ese sentido, nos parece que la representación directa y la estructura abierta de la discusión que es propia del Poder legislativo ${ }^{90}$ dotan de mayor legitimidad a su interpretación de lo que es o no un derecho fundamental en un momento histórico concreto, aunque ciertamente está lejos de premunirlo de infalibilidad ${ }^{91}$.

Pero un planteamiento prescriptivo como el nuestro tendría varias consecuencias relevantes para el sistema jurisdiccional en su conjunto. Tres de las más importantes son las siguientes. En primer lugar, que un juez ordinario no debería tener la prerrogativa de fallar a favor de un supuesto derecho fundamental implícito; en segundo lugar, que la jurisprudencia del Tribunal Constitucional que verse sobre tales derechos no debería tener carácter de precedente vinculante; y en tercer lugar, que dicho tribunal no debería declarar la inconstitucionalidad de una ley aun cuando tenga la convicción de que la misma viola un derecho no argumentable como explícito en la Constitución. Ahora bien, hay que reconocer que en un escenario como el que planteamos, un juez tendría razones tanto para fallar en favor del reconocimiento del derecho implícito invocado: un criterio jurisprudencial precedente del TC, como para no hacerlo: la Constitución política del país, lo que nos llevaría a que no haya certeza sobre si el derecho en disputa pertenece o no al sistema jurídico. Creemos que de darse una inseguridad jurídica de tal naturaleza, el responsable de la reforma constitucional debería intervenir en rigor, ya sea confirmando el criterio del Tribunal y haciendo expreso en el texto de la Constitución el derecho implícito tutelado por este y por los jueces ordinarios que hayan secundado su jurisprudencia ${ }^{92}$, ya sea negando expresamente la existencia de tal derecho, y por tanto, impidiendo legítimamente que los jueces del país -incluyendo al máximo intérprete de la Constitución, desde luego- continúen fallando por la tutela del supuesto derecho fundamental implícito en disputa.

\footnotetext{
89 Para MacCormick, más allá de la soberanía legal, la soberanía política sería aquel poder político que no está bajo el control de uno superior; mientras que el poder político sería la capacidad de tomar decisiones efectivas en orden al bien común de una sociedad. Confrontar MACCormick (2002) p. 127.

90 Ver, por ejemplo: Finnis (2016) pp. 9 ss.

${ }_{91}$ Nos parece que una idea semejante está detrás de la prevención de Waldron sobre lo que llama "dificultad democrática” respecto del control fuerte de constitucionalidad en general. Revisar WALDrON (2018) pp. 19 ss. Por otro lado, para un análisis de cómo el TC, a través del control preventivo de constitucionalidad de las leyes, participa hoy en el contrapeso de los poderes del Estado en el caso chileno, se puede revisar Meléndez Ávila (2017) pp. 185 ss.

92 Un caso interesante en el Perú fue el del "derecho al agua potable" confrontar TAVARA CAFERINO CON SEDAPAL (2008) F.J. 18, que fue reconocido como implícito por el TC, para luego ser añadido formalmente al catálogo de la CPP (art. $7^{\circ}$-A) a través de la Ley de Reforma Constitucional Nº 30588.
} 
Para terminar este acápite, baste insistir por ahora en que para nuestra propuesta, conjugar la dimensión tanto natural como positiva en materia de derechos implícitos implicaría que los Tribunales Constitucionales tengan sobre los mismos una función estrictamente jurisdiccional de tutela subjetiva de la dignidad en el caso concreto, pero de ninguna manera una función institucional análoga a la constituyente; y ello aunque suela plantearse en la doctrina que o bien dichos tribunales tienen que tener de alguna manera ambas funciones $^{93}$, o más bien no deberían tener prácticamente ninguna de ellas ${ }^{94}$. A esta propuesta de comprensión de los derechos fundamentales implícitos, podríamos denominarla "iusnaturalismo moderado".

\section{ALGUNAS VENTAJAS DE NUESTRA PROPUESTA}

Nos parece que el cuerpo doctrinal propuesto en el acápite anterior -a pesar de no haberse desarrollado exhaustivamente, y de no resultar pacífico- tiene algunas ventajas en orden a conjugar más convenientemente las dimensiones moral e institucional del derecho. Por ello nos ocuparemos en seguida, al menos, de las tres más relevantes, la primera referida estrictamente al fundamento de los derechos implícitos, y las dos restantes con una incidencia mayor sobre su caracterización.

En primer lugar, estaríamos frente a un fundamento de los derechos no positivo o natural de tipo ontológico: la dignidad humana, pero también frente a uno positivo e institucional, complementario y subordinado: la soberanía del pueblo, que legitiman en conjunto al Estado democrático de derecho, y plantean de cara al concepto de los derechos una suerte de combinación jerarquizada de lo que Alexy ha llamado concepto "sustancial" y concepto "formal" de los derechos fundamentales". Quizá valga la pena también dejar al menos anotado, que a nuestro modo de ver, la soberanía del pueblo en materia de derechos fundamentales tiene una función importante, aunque solo de carácter "interpretativo", es decir, de reconocimiento y de formulación histórica de dichos derechos morales, prepositivos o naturales ${ }^{96}$. Estos derechos, al ser inherentes y universales, tendrían que residir más bien en lo único capaz en la persona de tener dichas características y de plantear una esencial igualdad de trato para todos: los fines propios de su naturaleza humana, la que termina siendo fuente de su dignidad ${ }^{97}$; y no en una mera autonomía moral, de carácter más bien contingente y gradual ${ }^{98}$, aun cuando se intente plantear - a nuestro juicio, sin justificación suficiente sobre esa base- como igual para todos los miembros de la especie humana ${ }^{99}$. En última instancia, hablamos aquí de un fundamento de los derechos de carácter meta-

\footnotetext{
93 Confrontar, por ejemplo: SÁEnZ Dávalos (2009) pp. 47 ss.

94 Ver, por ejemplo: CANDia FALCÓn (2014) pp. 506 ss.

95 Confrontar Alexy (2007a) pp. 48-51.

96 Para una defensa de dicho sentido "interpretativo", confrontar ChÁvez-Fernández Postigo (2017) pp. 296 ss.

97 Confrontar, por ejemplo: Castillo Córdova (2008) p. 38.

98 Revisar, por ejemplo: AtienZa (2010) p. 186.

99 Confrontar, por ejemplo: Hierro (2016) pp. 131 ss. En nuestra opinión, desvincular la dignidad de la naturaleza humana hace que el empleo iusfundamental del término "dignidad" devenga en meramente retórico. Sobre los peligros de un uso puramente retórico de la dignidad, confrontar CHUECA (2015) pp. 25 ss.
} 
físico muy cercano al sentido clásico ${ }^{100}$, y no en el sentido solo "constructivo" del modelo alexiano $^{101}$.

En segundo lugar, por más que pueda parecer paradójico que hablar de "derechos naturales" pueda ser compatible con conjugar más convenientemente justicia con seguridad jurídica, lo cierto es que si asumimos que los derechos fundamentales implícitos en sentido propio son "derechos naturales", parece que hay que aceptar también que estos difícilmente podrían resultar del todo desconocidos para el común de los ciudadanos, dado que sus contenidos materiales tendrían por base los fines perfectivos propios de lo que nos hace humanos. Es verdad que ello no garantiza que siempre se acierte al juzgar sobre su existencia o su contenido, pero creemos que al menos existiría una pauta objetiva y cognoscible para la discusión de su razonabilidad histórica: la común naturaleza humana ${ }^{102}$. Desde luego, si se prefiere negar la tesis de la naturaleza humana, y defender más bien que la dignidad que justifica los derechos se encuentra en la mera autonomía moral del sujeto, a nuestro modo de ver, dicha labor interpretativa no solo se hace más difícil, sino que resulta prácticamente imposible, puesto que la mera autonomía - por su propio estatuto formal- no puede ofrecer al justiciable contenidos materiales determinativos de carácter objetivo para la dirección de su acción, y cualquier potestad podría ser pasible de ser argumentada con éxito plausible como derecho fundamental implícito ${ }^{103}$.

En tercer lugar, precisamente por lo anterior, nos parece conveniente que se pueda hablar de derechos humanos y fundamentales en sentido propio e impropio. Somos de la idea de que ello es más consistente respecto de la tesis de que el reconocimiento positivo o institucional de dichos bienes debidos en justicia es solo histórico y contingente, por lo que se abre la posibilidad al menos teórica de que: a) hayan existido en el pasado derechos no reconocidos por la Constitución, y en ese sentido esta haya sido promulgada con ese déficit axiológico-jurídico; b) puedan aparecer con posterioridad a la promulgación constitucional "nuevos derechos", no por la mutación del fundamento moral que tiene más bien carácter permanente, sino por el cambio de las circunstancias históricas en que se expresa socialmente en términos de justicia la dignidad humana ${ }^{104}$, o c) pueda darse un reconocimiento constituyente o jurisprudencial en realidad fallido o no razonable de los mismos ${ }^{105}$.

\section{COLOFÓN}

Para concluir, baste señalar que creemos que un "iusnaturalismo moderado" respecto de los derechos fundamentales implícitos como el que hemos esbozado aquí a partir del examen de las jurisprudencia constitucional de Perú y de Chile a la luz de la tesis no positivista de la doble naturaleza del derecho de Robert Alexy, no obstante no ser pacífica, puede aportar a resolver el desafío que la tesis de la existencia de derechos implícitos le plantea

100 Revisar, por ejemplo: Aristóteles (1998) V, 3, 1014b, pp. 16 ss.

101 Para una crítica de la metafísica que sostiene el concepto alexiano de dignidad, revisar SODERo (2017) pp. 93 ss.

102 Confrontar, por ejemplo: Finnis (2004) pp. 176-180.

103 Revisar, por ejemplo: Kaufmann (2007) pp. 43 ss.

104 Ver Chávez-Fernández Postigo y Valdivia Aguilar (2016) pp. 68 ss.

105 Confrontar Trujillo (2005) pp. 234-235. 
al contemporáneo Estado Constitucional de Derecho, al menos en los dos aspectos a los que nos hemos circunscrito en este trabajo. En primer lugar, porque permite conjugar más convenientemente las dimensiones natural y positiva de los derechos fundamentales: estrechamente vinculadas a la justicia y a la seguridad jurídica, respectivamente. En segundo lugar, porque lo hace velando por el carácter institucional de los derechos, sin descuidar el aspecto subjetivo de los mismos que mira sobre todo a la tutela efectiva de la dignidad del justiciable en toda circunstancia concreta.

\section{BIBLIOGRAFÍA CITADA}

AleXY, Robert (2000): “La institucionalización de la razón”, Persona y derecho, $\mathrm{N}^{\circ} 43$ : pp. 217-250.

AleXY, Robert (2006): "Una defensa de la fórmula de Radbruch", en Vigo, Rodolfo Luis (edit.), La injusticia extrema no es derecho. (De Radbruch a Alexy) (trad. José Antonio Seoane, Buenos Aires, La Ley, primera reimpresión) pp. 227-251.

AleXY, Robert (2007a): Teoría del discurso y derechos constitucionales (trad. Pablo Larrañaga, México, Fontamara, primera reimpresión).

Alexy, Robert (2007b): Teoría de los derechos fundamentales (trad. Carlos Bernal Pulido, Madrid, CECP).

AleXY, Robert (2009): Teoría del discurso y derechos humanos (trad. Luis Villar Borda, Bogotá, Universidad Externado de Colombia, primera reimpresión).

Alexy, Robert (2011a): "La doble naturaleza del derecho", en Bernal Pulido, Carlos (edit.), La doble dimensión del derecho. Autoridad y razón en la obra de Robert Alexy (trad. Jorge Portocarrero Quispe, Lima, Palestra), pp. 29-58.

AleXY, Robert (2011b): "Algunas reflexiones en torno a cómo mi pensamiento jurídico ha ido desarrollándose con el paso de los años", en Bernal Pulido, Carlos (edit.): La doble dimensión del derecho. Autoridad y razón en la obra de Robert Alexy (trad. Jorge Portocarrero Quispe, Lima, Palestra), pp. 59-87.

Alexy, Robert (2013): “El no-positivismo incluyente”, Doxa, N³6: pp. 15-23.

Alexy, Robert (2016a): "Un concepto no positivista de derecho fundamental. Sobre la relación entre Teoría de los principios, derechos fundamentales y moral”, en ELÓSEGUI ITXASO (coord.), Los principios y la interpretación judicial de los derechos fundamentales. Homenaje a Robert Alexy en su 70 aniversario (trad. Bibiana Erustes, Claudia Müller y Úrsula Siebert, Zaragoza, Marcial Pons), pp. 27-45.

AleXY, Robert (2016b): "La existencia de los derechos humanos", en AleXY, Robert, La institucionalización de la justicia (trad. Alfonso Ballesteros y José Antonio Seoane, Granada, Comares, tercera edición ampliada), pp. 91-107.

Alexy, Robert (2016c): "Derecho, discurso y tiempo", en AleXY, Robert, La institucionalización de la justicia (trad. Pablo Rodríguez y José Antonio Seoane, Granada, Comares, tercera edición ampliada), pp. 59-74.

AleXY, Robert (2016d): “¿Derechos humanos sin metafísica?”, en AleXY, Robert, La institucionalización de la justicia (trad. José Antonio Seoane y Eduardo Sodero, Granada, Comares, tercera edición ampliada), pp. 75-89. 
Alexy, Robert (2017a): “The Ideal Dimension of Law”, en Duke, George and George, Robert P. (edit.), The Cambridge Companion to Natural Law Jurisprudence (New York, Cambridge University Press), pp. 314-341.

Alexy, Robert (2017b): "The Absolute and the Relative Dimensions of Constitutional Rights", Oxford Journal of Legal Studies, No 37: pp. 31-47.

AleXY, Robert (2018): "The Special Case Thesis and the Dual Nature of Law", Ratio Juris, No 31: pp. 254-259.

Aristóteles (1998): Metafísica (trad. Valentín García Yebra, Madrid, Gredos, segunda edición revisada).

Aristóteles (2003): Ética Nicomáquea / Ética Eudemia (trad. Julio Pallí Bonet, Madrid, Gredos, sexta reimpresión).

AtienZa, Manuel (2010): “Sobre el concepto de dignidad humana”, en Atienza, Manuel, Bioética, derecho y argumentación (Lima, Palestra), pp. 259-302.

Bernal Pulido, Carlos (2011): "La tesis de la doble naturaleza del derecho. Estudio introductorio", en Bernal Pulido, Carlos (edit.), La doble dimensión del derecho. Autoridad y razón en la obra de Robert Alexy (trad. Jorge Portocarrero Quispe, Lima, Palestra) pp. 7-27.

Bulygin, Eugenio (1987): "Sobre el estatus ontológico de los derechos humanos", Doxa, No 4: pp. 259-278.

Candia Falcón, Gonzalo (2011): “Analizando la tesis de los derechos implícitos: Comentario a la sentencia del Tribunal Constitucional recaída sobre el requerimiento de Inaplicabilidad Rol No 2.408-2013 de 6 de marzo de 2014", Revista de Derecho Universidad Católica de Norte, Año 21, No 1: pp. 497-521.

Carpio Marcos, Edgar (2000): "El significado de la cláusula de los derechos no enumerados", Cuestiones Constitucionales, N 3: pp. 3-25.

Carpio Marcos, Edgar (2008): "Los derechos no enumerados en la Constitución y la jurisprudencia del Tribunal Constitucional”, Gaceta constitucional: jurisprudencia de observación obligatoria para abogados y jueces, No 5: pp. 17-21.

Castillo Córdova, Luis (2007): Los derechos constitucionales. Elementos para una teoría general (Lima, Palestra, tercera edición).

Castillo Córdova, Luis (2008): "Justificación y significación de los derechos constitucionales implícitos”, Gaceta constitucional: jurisprudencia de observación obligatoria para abogados y jueces, No 5: pp. 31-48.

Cea Egaña, José Luis (2012): Derecho Constitucional chileno. Tomo II: Derechos, deberes y garantías (Santiago, Ediciones Universidad Católica de Chile, segunda edición).

Chávez-Fernández Postigo, José (2012): La dignidad como fundamento de los derechos humanos en las sentencias del Tribunal Constitucional peruano. La tensión entre la mera autonomía y la libertad ontológica (Lima, Palestra).

Chávez-Fernández Postigo, José (2017): Luis Recaséns y la Teoría estándar de la argumentación jurídica. Una revalorización del logos de lo razonable (Pamplona, Thomson Reuters).

Chávez-Fernández Postigo, José y Valdivia Aguilar, Trilce (2016): "Entre derechos implícitos y derechos naturales: la Corte IDH y la no discriminación por orientación sexual en el caso Atala”, Díkaion, N²5, pp. 53-74. 
Chueca, Ricardo (2015): "La marginalidad jurídica de la dignidad humana", en Chueca, Ricardo (dir.), Dignidad humana y derecho fundamental (Madrid, CEPC), pp. 25-52.

Cianciardo, Juan (2017): "Problemas que una nota esencial de los derechos humanos continúa planteando a la Filosofía del derecho", Persona y derecho, Nº 75: pp. 83-91.

Contreras Vásquez, Pablo (2011): “¿Derechos implícitos? Notas sobre la identificación de normas de derecho fundamental, en NúNEzz LeIva, José (edit.), Nuevas perspectivas en derecho público (Santiago, Librotecnia), pp. 149-185.

Correa SutiL, Jorge (2011): Inaplicabilidad por inconstitucionalidad en la jurisprudencia del Tribunal Constitucional (Santiago, AbeledoPerrot).

Fernández González, Miguel (1989): "Reforma al Artículo 5 de la Constitución", Revista Chilena de Derecho, Vol. 16, No 3: pp. 809-826.

FinNis, John (2004): Aquinas. Moral, Political, and Legal Theory (New York, Oxford University Press, reprinted).

FinNIS, John (2011): Natural Law and Natural Rights (New York, Oxford University Press, second edition).

FinNis, John (2016): “Judicial Power: Past, Present and Future”. Disponible en: http://judicialpowerproject.org.uk/wp-content/uploads/2015/10/John-Finnis-lecture-20102015. pdf. Fecha de consulta: 22 de noviembre de 2017.

Evans de la Cuadra, Enrique (1999): Los derechos constitucionales, Tomo I (Santiago, Editorial Jurídica de Chile, segunda edición).

Hervada, Javier (1982): "Problemas que una nota esencial de los derechos humanos plantea a la Filosofía del derecho", Persona y derecho, No 9: pp. 243-256.

Hierro, Liborio (2016): Los derechos humanos. Una concepción de la justicia (Madrid, Marcial Pons).

Kant, Immanuel (2005): La Metafísica de las costumbres (trad. Adela Cortina Ortis y Jesús Conill Sancho, Madrid, Tecnos, cuarta edición).

Kaufmann, Arthur (2007): La Filosofía del derecho en la Posmodernidad (trad. Luis Villar Borda, Bogotá, Temis, tercera edición).

MacCormick, Neil (2002): Questioning sovereignty. Law, State, and Nation in the European Commonwealth (New York, Oxford University Press, reprinted).

MelÉNDEZ Ávila, Felipe (2017): El control preventivo en la Constitución actual: el temor al desborde gubernamental en la función legislativa (Santiago, Editorial Jurídica de Chile).

Nash, Claudio (2006): "Los derechos fundamentales: el desafío para el constitucionalismo chileno del siglo XXI", en Konrad Adenauer Stiftung, Anuario de derecho constitucional latinoamericano, Volumen No 2: pp. 1305-1333.

Nogueira, Humberto (2005): "Aspectos de una teoría de los derechos fundamentales: la delimitación, regulación, garantías y limitaciones de los derechos fundamentales", Ius et Praxis, Vol. 11, No 2, pp. 15-54.

Nogueira, Humberto (2007) "El derecho a la propia imagen como derecho fundamental implícito: fundamentación y caracterización”, Ius et Praxis, Vol. 13, No 2: pp. 245-285.

Pérez Luño, Antonio Enrique (2010): Derechos humanos, Estado de Derecho y Constitución (Madrid, Tecnos, décima edición). 
Ruiz-Tagle Vial, Luis (2003): "Los derechos fundamentales en el siglo XXI y la disminución de su efecto mariposa", Revista de Derecho, Vol. 15: pp. 181-190.

SÁenz Dávalos, Luis (2009): "Los derechos no enumerados y sus elementos de concretización", en SÁEnz DÁvalos, Luis (coord.), Derechos constitucionales no escritos reconocidos por el Tribunal Constitucional (Lima, Gaceta Jurídica), pp. 13-47.

Sodero, Eduardo (2017): "Concepto de derecho, moral y dignidad en Robert Alexy: de la argumentación a la metafísica”, en AlEXY, Robert et al. (coord.), Argumentación, derechos humanos y justicia (Buenos Aires, Astrea), pp. 49-105.

Sosa SAcio, Juan (2009): "Derechos constitucionales no enumerados y el derecho al libre desarrollo de la personalidad", en SÁenz DÁvalos, Luis (coord.), Derechos constitucionales no escritos reconocidos por el Tribunal Constitucional (Lima, Gaceta Jurídica), pp. 97-147.

STARCK, Christian (2011): "Introducción a la dignidad humana en el derecho alemán", en STARCK, Christian: Jurisdicción constitucional y derechos fundamentales (trad. Alberto Oehling de los Reyes, Madrid, Tecnos, décima edición), pp. 127-133.

Troncoso, Claudio y Tomás Vial (1993): "Sobre los derechos humanos reconocidos en Tratados internacionales y en la Constitución”, Revista Chilena de Derecho, Vol. 20, No 2-3: pp. 695-704.

TRujilLo, Isabel (2005): "Derechos y falsos derechos: derechos razonables y no razonables", Persona y derecho, No 52: pp. 219-236.

Vivanco Martínez, Ángela (1998): “Cuestionamiento del modelo constitucional: una reflexión acerca de la ética individual, los nuevos derechos y el regreso a la paradoja de la tolerancia”, Revista Chilena de Derecho, Vol. 1998, Número Especial: pp. 103-113.

Waldron, Jeremy (2013): "Is Dignity the Foundation of Human Rights?", New York University Public Law and Legal Theory Working Papers. Paper 374. Disponible en: http://lsr.nellco.org/nyu_plltwp/374. Fecha de consulta: 22 de noviembre de 2017.

Waldron, Jeremy (2018): "Control de constitucionalidad y legitimidad", Dikaion, No 27: pp. 7-28.

\section{NORMAS CITADAS}

Naciones Unidas, Asamblea General, 217 A(III) (10 de diciembre de 1948), Declaración Universal de Derechos Humanos.

Convenio para la Protección de los Derechos Humanos y las Libertades Fundamentales, Roma (4 de noviembre de 1950).

Pacto Internacional de Derechos Civiles y Políticos (Nueva York, 16 de diciembre de 1966).

Convención Americana sobre Derechos Humanos (San José, 22 de noviembre de 1969).

Constitución Política de la República de Chile (1980).

Constitución Política del Perú (1993).

Código Procesal Constitucional del Perú, Ley Nº 28237 (2004). 


\section{JURISPRUDENCIA DEL TC PERUANO CITADA}

CANChARI PISCO CON COMSTEA (1999): Tribunal Constitucional peruano, Expediente No 00316-1998-AA/TC. Sentencia: 31 de julio de 1999.

DEMANDA DE INCONSTITUCIONALIDAD CONTRA LA LEY N 27766 (2002): Tribunal Constitucional peruano, Expediente No 0011-2002-AI/TC. Sentencia: 10 de junio de 2002.

Sarmiento Bejarano con Mestanza Robles (2003): Tribunal Constitucional peruano, Expediente No 01257-2000-AA/TC. Auto: 28 de enero de 2003.

Rosado AdANAQUe CON ESSALUD (2003): Tribunal Constitucional peruano, Expediente No 0895-2001-AA/TC. Sentencia: 16 de marzo de 2003

VILLEGAS NAMUCHE CON ESTAdo PERUANO (2004): Tribunal Constitucional peruano, Expediente No 02488-2002-HC/TC. Sentencia: 22 de marzo de 2004.

ANICAMA HERNÁNDEZ CON ONP (2005): Tribunal Constitucional peruano, Expediente No 01417-2005-AA/TC. Sentencia: 12 de junio de 2005

VILLANUEVA VALVERDE CON ONP (2005): Tribunal Constitucional peruano, Expediente No 00168-2005-AC/TC Sentencia: 3 de octubre de 2005.

DEMANDA DE INCONSTITUCIONALIDAD CONTRA LA LEY N 28617 (2006): Tribunal Constitucional peruano, Expediente No 00030-2005-AI/TC. Sentencia: 10 de febrero de 2006.

DEMANDA DE INCONSTITUCIONALIDAD CONTRA EL ARTÍCULO 22으. INCISO C) DE LA LEY N 26397 (2006); Tribunal Constitucional peruano, Expediente No 0025-2005-AI/TC. Sentencia: 15 de agosto de 2006.

MANUCA QUIROZ CON RENIEC (2006): Tribunal Constitucional peruano, Expediente $\mathrm{N}^{\circ}$ 02273-2005-HC/TC. Sentencia: 13 de octubre de 2006.

DEMANDA DE INCONSTITUCIONALIDAD CONTRA LAS ORDENANZAS Nos 212-2005 y N.o 214-2005 de la Municipalidad Distrital de Miraflores (2007): Tribunal Constitucional peruano, Expediente $\mathrm{N}^{\circ}$ 00007-2006-AI/TC. Sentencia: 20 de febrero de 2007.

ZÚNIIGA LÓPEZ CON EPSEL S.A (2007): Tribunal Constitucional peruano, Expediente $\mathrm{N}^{\circ}$ 06546-2006-AA/TC. Sentencia: 21 de diciembre de 2007.

Empresa de TRANSPORTes TuRismo Imperial S.A CON MTC (2008). Tribunal Constitucional peruano, Expediente No 01535-2006-AA/TC. Sentencia: 31 de enero de 2008.

TÁvara CAFERINO CON SEDAPAL (2008): Tribunal Constitucional peruano, Expediente N 06534-2006-AA/TC. Sentencia: 22 de febrero de 2008.

AMANQUI RAMOS CON RENIEC (2008): Tribunal Constitucional peruano, Expediente $\mathrm{N}^{\circ}$ 02432-2007-HC/TC. Sentencia: 23 de enero de 2008.

DEMANDA DE INCONSTITUCIONALIDAD CONTRA EL ARTÍCULO $3^{\circ}$ DE LA LEY No 28705 (2011): Tribunal Constitucional peruano, Expediente $N^{\circ}$ 00032-2010-AI/TC. Sentencia: 21 de agosto de 2011.

DEMANDA DE INCONSTITUCIONALIDAD CONTRA LA LEY No 29951 (2015): Tribunal Constitucional peruano, Expedientes No 00003-2013-AI/TC, No 00004-2013-AI/TC, y N ${ }^{\circ}$ 00023-2013-AI/TC (acumulados). Sentencia: 14 de setiembre de 2015.

DEMANDA DE INCONSTITUCIONALIDAD CONTRA DIVERSOS ARTÍCULOS DE LA LEY N 30057 (2016): Tribunal Constitucional peruano, Expedientes No 0025-2013-AI/TC, No 0003-2014AI/TC, $N^{\circ}$ 00008-2014-AI/TC y N0017-2014-AI/TC (acumulados), Sentencia: 26 de abril de 2016. 


\section{JURISPRUDENCIA DEL TC CHILENO CITADA}

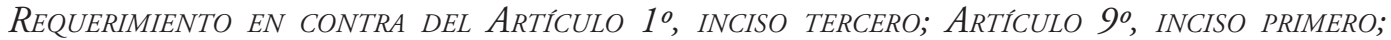
Artículo 20․ inciso segundo y ARtículo 43o, inciso segundo, del Proyecto de Ley SOBRE LIBERTAD DE EXPRESIÓN, INFORMACIÓN, Y EJERCICIO DEL PERIODISMO, DEDUCIDO POR LA CUARTA PARTE DE LOS DIPUTADOS (1995): Tribunal Constitucional chileno, Rol No 226, 30 de octubre de 1995.

Control de Constitucionalidad del Proyecto de Ley que crea la Unidad de Análisis

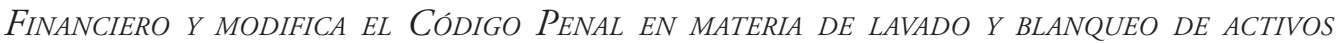
(2003): Tribunal Constitucional chileno, Rol No 389, 18 de diciembre de 2003.

Control de Constitucionalidad del Proyecto de Ley que sustituye la Ley No 19.366, QUE SANCIONA EL TRÁFICO ILÍCITO DE ESTUPEFACIENTES Y SUSTANCIAS SICOTRÓPICAS (2005): Tribunal Constitucional chileno, Rol No 433, 16 de febrero de 2005.

REQUERIMIENTO DE INAPLICABILIDAD POR InCONSTITUCIONALIDAD DEL ARTÍCULO $13^{\circ}$ DE LA LEY No 15.575, ORGÁNICA CONSTITUCIONAL DE BASES GENERALES DE LA ADMINISTRACIÓN DEL ESTADO, FORMULAdo POR LA CORTE DE APELACIONES DE VALPARAÍso (2006): Tribunal Constitucional, Rol No 634, 9 de agosto de 2007.

REQUERIMIENTO DE INAPLICABILIDAD POR INCONSTITUCIONALIDAD DELOS ARTÍCULO $1^{\circ}$, INCISO SEgundo Y $292^{\circ}$ del Código Penal, deducido por Hartmut Wilhem Hopp Miottel (2007): Tribunal Constitucional chileno, Rol No 739, 21 de agosto de 2007.

REQUERIMIENTO DEDUCIDO POR DIVERSOS DIPUTADOS, EN CONFORMIDAD AL ARTÍCULO 93, $N^{\circ} 3$,

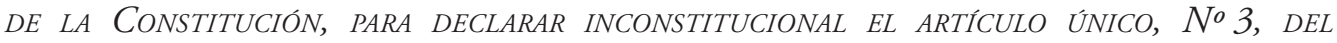
PROYECTO DE LEY MODIFICATORIO DE LA LEY No 20.084, QUE ESTABLECE UN SISTEMA DE RESPONSABILIDAD DE LOS ADOLESCENTES POR INFRACCIONES A LA LEY PENAL, EN LA PARTE EN QUE DICHA NORMA MODIFICA EL ARTÍCULO 23, No 1 DEL CITADO CUERPO LEGAL (2007): Tribunal Constitucional chileno, Rol No 786, 3 de junio de 2007.

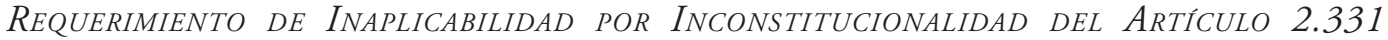
del Código CiVil, deducido por Luis Carlos VAldés Correa (2007): Tribunal Constitucional chileno, Rol No 943-2007, 10 de junio de 2008.

REQUERIMIENTO DE INAPLICABILIDAD POR INCONSTITUCIONALIDAD DEL ARTÍCULO 474, INCISO tercero, del Código del TRabajo, deducido por Sociedad FM SEGURIdad S.A. (2007): Tribunal Constitucional chileno, Rol No 946-2007, 1 de junio de 2008.

PROCESO INICIADO DE OfICIO PARA DECIDIR SOBRE LA CONSTITUCIONALIDAD DEL ARTÍCULO $38^{\circ}$ TER DE LA LEY DE ISAPRES Y CUYA SENTENCIA SE PUBLICÓ EN EL DIARIO OFICIAL EL 9 DE AGOSTO DE 2010 (2010), Tribunal Constitucional chileno, Rol No 1.710, 6 de agosto de 2010.

REQUERIMIENTO DE INAPLICABILIDAD POR INCONSTITUCIONALIDAD DEL ARTICULO $1^{\circ}$ INCISO SEGUN-

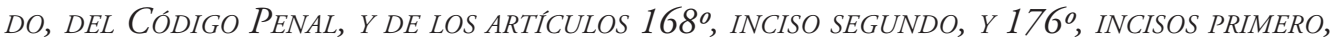
No 2 Y SEGUNDO, DE LA ORDENANZA GENERAL DE ADUANAS, EN RELACIÓN CON EL ARTÍCULO 21 DE LA LEY No 18.483, QUE ESTABLECE UN NUEVO RÉGIMEN LEGA PARA LA INDUSTRIA AUTOMOtriz, deducido por Pablo Rosas Montecinos y EdUardo VALECH Rubio (2009): Tribunal Constitucional chileno, Rol No 1.351, 20 de mayo de 2010. 
Requerimiento de Inaplicabilidad del artículo 206 del Código Civil, deducido POR EL JUZGADO DE FAMILIA dE VALDIVIA (2009): Tribunal Constitucional Chileno, Rol No 1.563, 30 de agosto de 2011.

REQUERIMIENTO DE INAPLICABILIDAD POR INCONSTITUCIONALIDAD DEL ARTICULO 206 DEL CÓDIGO Civil, deducido por Nel Greeven Bobadilla, Juez de Familia de Pudahuel (2010): Tribunal Constitucional chileno, Rol No 1.656, 1 de septiembre de 2011.

REQUERIMIENTO DE INAPLICABILIDAD POR INCONSTITUCIONALIDAD DEL ARTÍCULO 5o, INCISO SE-

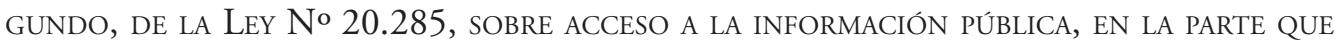
DICE " $Y$ TODA OTRA INFORMACIÓN QUE OBRE EN PODER DE LOS ÓRGANOS DE LA ADMINISTRACIÓN, CUALQUIERA SEA SU FORMATO, SOPORTE, FECHA DE CREACIÓN, ORIGEN, CLASIFICACIÓN O PROCesamiento, deducido por Claudio Alvarado Andrade, Subsecretario General de la Presidencia, en REPRESENTACIÓN DEL MiNISTERIo SeCRETaRÍa GENERAL DE LA PRESIDENCIA Y Christian Larroulet Vignau, Ministro Secretario General de la Presidencia, por sí (2012): Tribunal Constitucional chileno, Rol No 2.246, 31 de enero de 2013.

Requerimiento de Inaplicabilidad del artículo 206 Del Código CiVIL, DEDUCido por el Juez subrogante del Juzgado de Familia de Pitrufquén (2013): Tribunal Constitucional Chileno, Rol No 2.408, 6 de marzo de 2014. 